TAO, Vol. 13, No. 2, 135-152, June 2002

\title{
A Study of Strong Motion Response Spectrum in West-central Taiwan
}

\author{
Tian-Pau Chang ${ }^{1,2, *}$ and Guey-Kuen $\mathrm{Yu}^{2}$ \\ (Manuscript received 19 November 2001, in final form 18 April 2002)
}

\begin{abstract}
In this paper, a total of 901 free-field accelerograms recorded at the stations in west-central Taiwan from 32 earthquakes that occurred in Taiwan area between 1993 and 1999 are separated as four data groups based on PGA levels, the station sites are classified into three types by their dominant periods of acceleration response spectra. The characteristics of response spectra in regard to both earthquake intensity and station type are analyzed. In order to highlight the behavior of the Chi-Chi mainshock, several kinds of comparisons of the near-fault responses have been made with those of far-field data. The results show that the response spectra increase generally with the earthquake intensity for all stations. The spectral shape in long period regions become more predominant if the soil condition is softer. The mean response spectra plus one standard-deviation of the ChiChi mainshock are significantly larger than the required values of the current seismic design code. In terms of the long-period range, the spectra of the Chi-Chi mainshock are larger than the mean value of 32 events by more than 200 times. The spectral ratios of vertical to horizontal component almost exceed 2/3; this phenomenon reflects the intensified vertical ground motion due to the thrusting movement of the Chelungpu fault. Therefore, a modified design code is suggested for applications to near-fault areas.
\end{abstract}

(Key words: Response spectra, Dominant period, Chelungpu fault)

\section{INTRODUCTION}

The importance of the response spectra approach for structural design is well known to earthquake engineers and seismologists. In a typical responșe spectrum, three amplified regions, i.e., the short period, or acceleration region, the intermediate period, or velocity region, and the long period, or displacement region, can be classified. In each region, the corresponding

\footnotetext{
${ }^{1}$ Center of General Education, Nankai College, Nantou 540, Taiwan, ROC

2 Institute of Geophysics, National Central University, Chungli 320, Taiwan, ROC

* Corresponding author address: Mr. Tian-Pau Chang, Center of General Education, Nankai College, Nantou 540, Taiwan, ROC; E-mail: t118@ms2.hinet.net
} 
ground motions are amplified most. The shape of response spectra is influenced by various parameters, such as magnitude, source mechanism, hypocentral distance, intensity and local soil conditions (Seed et al. 1976). One procedure for constructing site-dependent spectra is to estimate the three ground motion parameters (the peak acceleration, velocity, and displacement) for the sites which have the same soil conditions, and then multiply them by their corresponding amplification factors (Newmark et al. 1973; Mohraz 1976; Saffarini and Kabalawi 1999).

The problems of seismic resistant design are constantly discussed because of high seismicity in Taiwan area. In the past, many studies of response spectrum were focused on the whole island or a few important areas. Tsai et al.(1986) have shown that the observed acceleration response spectrum for fundamental periods below $0.4 \mathrm{~s}$ is dominant for the rock site, but the response spectrum between 0.8 and $1.6 \mathrm{~s}$ is more significant for the alluvium site. Wen (1988) has found that the shape of response spectra for alluvium site, in Lotung area, is dominant between 0.1 and $1 \mathrm{~s}$, and the shape for rock site is dominant between 0.1 and $0.5 \mathrm{~s}$. Several studies have been carried out with the objective to develop recommendations for the design response spectra for the whole Taiwan area (Loh et al. 1991; Chen and Cheng 2000), for the Taipei basin (Tsai and Tsai 1987; Chen et al. 2000), and for the Kaohsiung city (Hong and Chang 1993). Tsai and Huang (2000) analyzed the acceleration response spectra near the Chelungpu fault by data of the Chi-Chi earthquake, and show that the median of spectra acceleration will increase as the distance from the recording site to the rupture surface decreases. The similar results given by Chai et al. (2000) reveal that the spectral characteristics for sites near the Chelungpu fault are considerably different from those for sites far away from the fault. Furthermore, the near-source factors have been defined to modify the design response spectrum.

The pity is that the domestic studies have not been particularly focused on the west-central part of Taiwan. But, the population and commercial activities in this area are increasing fast. On September 21, 1999, a disastrous earthquake (the Chi-Chi mainshock) of magnitude $M_{L}=7.3$ struck this area (Wang et al. 2000). This earthquake caused many casualties and much building damage. But, on a positive note, this earthquake has also provided us with a lot of information and data which can be used to reduce potential losses from future earthquakes.

In this study, we selected 32 events, from 1993 to 1999, to analyze the response spectra in the west-central part of Taiwan. The accelerograms are separated into four data groups based on the level of peak ground acceleration (PGA). The station sites are classified as three types by their dominant periods of acceleration response spectra. The characteristics of response spectra in regard to both earthquake intensity and station type are analyzed. Both the appropriateness of site classification and the problems of structural seismic design will also be discussed. In order to highlight the behavior of the Chi-Chi mainshock, several kinds of comparison on the near-fault responses are made with those of far-field data.

\section{DATA COLLECTING AND PROCESSING}

The strong ground motion data recorded by the network of Taiwan Strong Motion Instrumentation Program (TSMIP) of the Central Weather Bureau (CWB) are used to analyze the characteristics of response spectra. The data consists of 32 earthquakes $\left(M_{L} \geq 4.0\right)$, which 


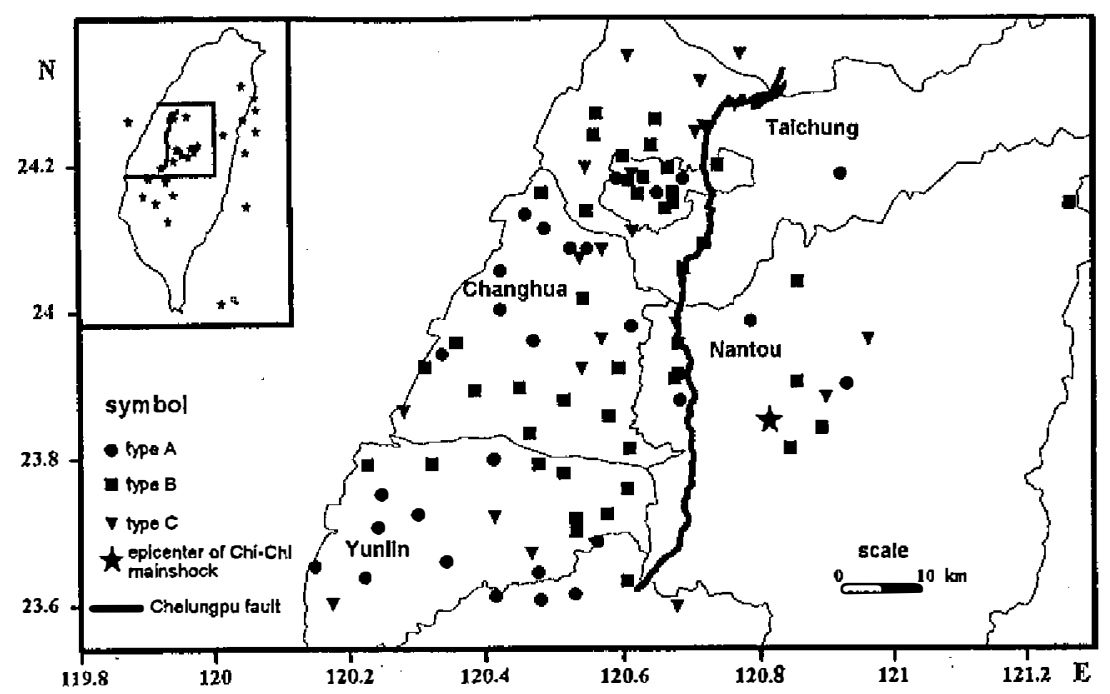

Fig. 1. Distribution of recording sites in west-central Taiwan. Solid circles, square and triangles are the sites of type $\mathrm{A}, \mathrm{B}$, and $\mathrm{C}$ respectively. Bold line is the fault Chelungpu, asterisk the epicenter of Chi-Chi mainshock. Epicenters for all the 32 events are also shown in the upper left.

occurred between 1993 and 1999 and were located within $120^{\circ} \sim 122^{\circ} \mathrm{E}$ and $22^{\circ} \sim 25^{\circ} \mathrm{N}$ (Fig. 1). The source parameters of these earthquakes are listed in Table 1. A total of 901 accelerograms with the PGA greater than 10 gal, from 103 stations located at Taichung, Changhua, Nantou, and Yunlin counties, are selected to analyze the response spectra. To help investigating the relationships between the spectral shape and the earthquake intensity, these accelerograms are separated into three data groups based on the PGA levels by above 10, 30, and 50 gal, and named $\mathrm{G}_{10}, \mathrm{G}_{30}$, and $\mathrm{G}_{50}$ group, respectively. In addition, the accelerograms of the Chi-Chi earthquake (mainshock only), near-fault data, are also treated as a special single group named $\mathrm{G}_{921}$. The number of records in each data group is listed in Table 2 .

To compute the response spectra, the base line correction should first be made to the original seismograms (Hong and Chang 1993; Chen and Cheng 2000). For doing this, the procedures are: (1) compute $5 \%$ damped response spectra for each station in frequency ranges from 0.1 to $100 \mathrm{~Hz}$ for three components. Here, the horizontal components are represented by the geometric mean value of North-South and East-West components; (2) compute the normalized response spectra (by parameter PGA); (3) compute the mean of normalized response spectra of each station for all events triggered at this station; (4) compute the total mean of response spectra (not yet normalized) for all stations in study area.

\section{SITE CLASSIFICATION}

In the current Taiwan Building Code (TBC), the sites are classified as three types by the dominant periods of ground $\left(\mathrm{T}_{\mathrm{G}}\right)$, for hard soil sites $\mathrm{T}_{\mathrm{G}} \leq 0.2 \mathrm{~s}$, for medium soil $0.2<\mathrm{T}_{\mathrm{G}} \leq 0.6 \mathrm{~s}$, 
Table 1. Source parameters of 32 earthquakes used in this study.

\begin{tabular}{|c|c|c|c|c|c|c|}
\hline No. & $\begin{array}{c}\text { Date } \\
(\mathrm{y} / \mathrm{m} / \mathrm{d})\end{array}$ & $\begin{array}{c}\text { Longitude } \\
\left({ }^{\circ} \mathrm{E}\right)\end{array}$ & $\begin{array}{c}\text { Latitude } \\
\left({ }^{\circ} \mathrm{N}\right)\end{array}$ & $\begin{array}{c}\text { Depth } \\
(\mathrm{km})\end{array}$ & $\begin{array}{c}\text { Magnitude } \\
\left(\mathrm{M}_{\mathrm{L}}\right)\end{array}$ & $\begin{array}{c}\text { Stations } \\
\text { Triggered }\end{array}$ \\
\hline 1 & $1993 / 12 / 13$ & 120.791 & 24.215 & 26.49 & 4.46 & 8 \\
\hline 2 & $1993 / 12 / 15$ & 120.524 & 23.213 & 12.50 & 5.70 & 27 \\
\hline 3 & $1994 / 01 / 20$ & 121.852 & 24.065 & 49.45 & 5.58 & 34 \\
\hline 4 & $1994 / 03 / 28$ & 120.687 & 22.985 & 14.37 & 5.41 & 11 \\
\hline 5 & $1994 / 04 / 06$ & 120.421 & 23.532 & 13.44 & 5.03 & 22 \\
\hline 6 & $1994 / 05 / 31$ & 120.770 & 23.715 & 7.84 & 4.57 & 17 \\
\hline 7 & $1994 / 06 / 05$ & 121.838 & 24.462 & 5.30 & 6.20 & 32 \\
\hline 8 & $1994 / 10 / 05$ & 121.720 & 23.156 & 31.28 & 5.83 & 42 \\
\hline 9 & $1995 / 01 / 19$ & 120.761 & 23.305 & 14.32 & 4.46 & 6 \\
\hline 10 & $1995 / 02 / 23$ & 121.687 & 24.204 & 21.69 & 5.77 & 78 \\
\hline 11 & $1995 / 06 / 25$ & 121.699 & 24.606 & 39.88 & 6.50 & 46 \\
\hline 12 & $1995 / 07 / 07$ & 121.090 & 23.893 & 13.07 & 5.30 & 57 \\
\hline 13 & $1995 / 07 / 14$ & 121.851 & 24.320 & 8.79 & 5.80 & 7 \\
\hline 14 & $1995 / 09 / 07$ & 120.966 & 23.764 & 24.75 & 4.34 & 9 \\
\hline 15 & $1995 / 09 / 28$ & 120.446 & 23.507 & 9.27 & 4.48 & 12 \\
\hline 16 & $1995 / 10 / 31$ & 120.359 & 23.291 & 10.65 & 5.19 & 7 \\
\hline 17 & $1996 / 04 / 07$ & 120.662 & 23.468 & 1.18 & 4.70 & 8 \\
\hline 18 & $1996 / 09 / 05$ & 121.367 & 22.001 & 14.76 & 7.07 & 8 \\
\hline 19 & $1996 / 12 / 15$ & 121.422 & 24.022 & 71.36 & 4.81 & 7 \\
\hline 20 & $1997 / 04 / 13$ & 121.714 & 23.805 & 45.49 & 5.56 & 45 \\
\hline 21 & $1997 / 05 / 02$ & 120.179 & 24.186 & 22.65 & 4.50 & 10 \\
\hline 22 & $1997 / 08 / 20$ & 120.943 & 24.246 & 37.39 & 4.40 & 6 \\
\hline 23 & $1997 / 10 / 29$ & 120.598 & 23.627 & 11.33 & 4.32 & 16 \\
\hline 24 & $1998 / 05 / 01$ & 120.166 & 24.203 & 16.71 & 4.35 & 5 \\
\hline 25 & $1998 / 07 / 17$ & 120.662 & 23.503 & 2.80 & 6.20 & 47 \\
\hline 26 & $1998 / 07 / 18$ & 120.694 & 23.513 & 1.81 & 4.51 & 9 \\
\hline 27 & $1998 / 08 / 16$ & 120.532 & 23.203 & 8.00 & 4.80 & 10 \\
\hline 28 & $1998 / 09 / 16$ & 120.840 & 23.836 & 26.33 & 4.50 & 26 \\
\hline 29 & $1999 / 09 / 20$ & 120.815 & 23.853 & 8.00 & 7.30 & 79 \\
\hline 30 & $1999 / 09 / 20$ & 120.876 & 23.792 & 3.50 & 6.60 & 79 \\
\hline 31 & $1999 / 09 / 22$ & 121.047 & 23.826 & 15.60 & 6.80 & 59 \\
\hline 32 & $1999 / 09 / 25$ & 121.006 & 23.859 & 9.90 & 6.80 & 72 \\
\hline
\end{tabular}


Table 2. Numbers of records and triggered stations in each data group.

\begin{tabular}{ccrcccc}
\hline Data group & $\begin{array}{c}\text { Site } \\
\text { type }\end{array}$ & $\begin{array}{c}\text { V } \\
\text { comp. }\end{array}$ & $\begin{array}{c}\text { NS } \\
\text { comp. }\end{array}$ & $\begin{array}{c}\text { EW } \\
\text { comp. }\end{array}$ & $\begin{array}{c}\text { H comp. } \\
\text { (NS+EW) }\end{array}$ & $\begin{array}{c}\text { Stations } \\
\text { triggered }\end{array}$ \\
\hline$G_{10}$ & A & 182 & 317 & 326 & 643 & 33 \\
(PGA $\geq 10$ gal) & B & 215 & 330 & 345 & 675 & 47 \\
& C & 83 & 150 & 154 & 304 & 23 \\
\hline \multirow{2}{*}{$G_{30}$} & A & 85 & 132 & 129 & 261 & 30 \\
$($ PGA $\geq 30$ gal) & B & 109 & 169 & 169 & 338 & 47 \\
& C & 45 & 65 & 65 & 130 & 21 \\
\hline \multirow{2}{*}{$G_{50}$} & A & 58 & 86 & 91 & 177 & 28 \\
$($ PGA $\geq 50$ gal) & B & 85 & 121 & 124 & 245 & 44 \\
& C & 33 & 46 & 49 & 95 & 21 \\
\hline$G_{921}$ & A & 25 & 25 & 25 & 50 & 25 \\
$($ Chi-Chi & B & 35 & 35 & 35 & 70 & 35 \\
mainshock $)$ & C & 19 & 19 & 19 & 38 & 19 \\
\hline
\end{tabular}

and for soft soil $\Upsilon_{\mathrm{G}}>0.6 \mathrm{~s}$, respectively. According to the wave theory, as the motion travels through the ground, the wave will be filtered out rapidly if its period differs from the ground period, and the shape of the response spectrum is profoundly influenced by the nature of the soil conditions underlying the site. For sites underlain by deposits of stiff soils, the peak ordinates of acceleration response spectra tend to occur at a low value of the fundamental period. On the other hand, for sites underlain by thick deposits of soft soils, the peak ordinates will tend to occur at a rather high value of the fundamental period (Seed and Idriss 1969; Seed et al. 1976; Mohraz 1976; Chen 1994). For example, the peaks presented by Seed et al.(1976) for four types of site condition, rock, stiff soil, deep cohesionless soil, and soft to medium clay and sand, are about $0.21,0.28,0.35$, and $0.85 \mathrm{~s}$ respectively. In this study, we classify the sites based on their dominant period (dp_a) of the mean acceleration response spectra, calculated from the accelerograms with PGA larger than 50 gal, i.e., $\mathrm{G}_{50}$ group, called type $\mathrm{A}$ if $\mathrm{dp} \_\mathrm{a} \leq 0$. $2 \mathrm{~s}$, type $\mathrm{B}$ if $0.2<\mathrm{dp} \_\mathrm{a} \leq 0.35 \mathrm{~s}$, and type $\mathrm{C}$ if dp_a $>0.35 \mathrm{~s}$.

\section{RESULT AND DISCUSSION}

\subsection{Comparison with the Results of Seed et al. (1976)}

The mean of normalized horizontal response spectra for three types, calculated from different data groups, as well as the four spectral shapes of Seed et al.(1976) are shown in Fig. 2. For any type of site, the response spectra increase gradually with the data groups from $\mathrm{G}_{10} \rightarrow \mathrm{G}_{30} \rightarrow \mathrm{G}_{50} \rightarrow \mathrm{G}_{921}$, particularly, in the long-period ranges. Moreover, for the same data group, the long-period energy also increases gradually with the site type from 

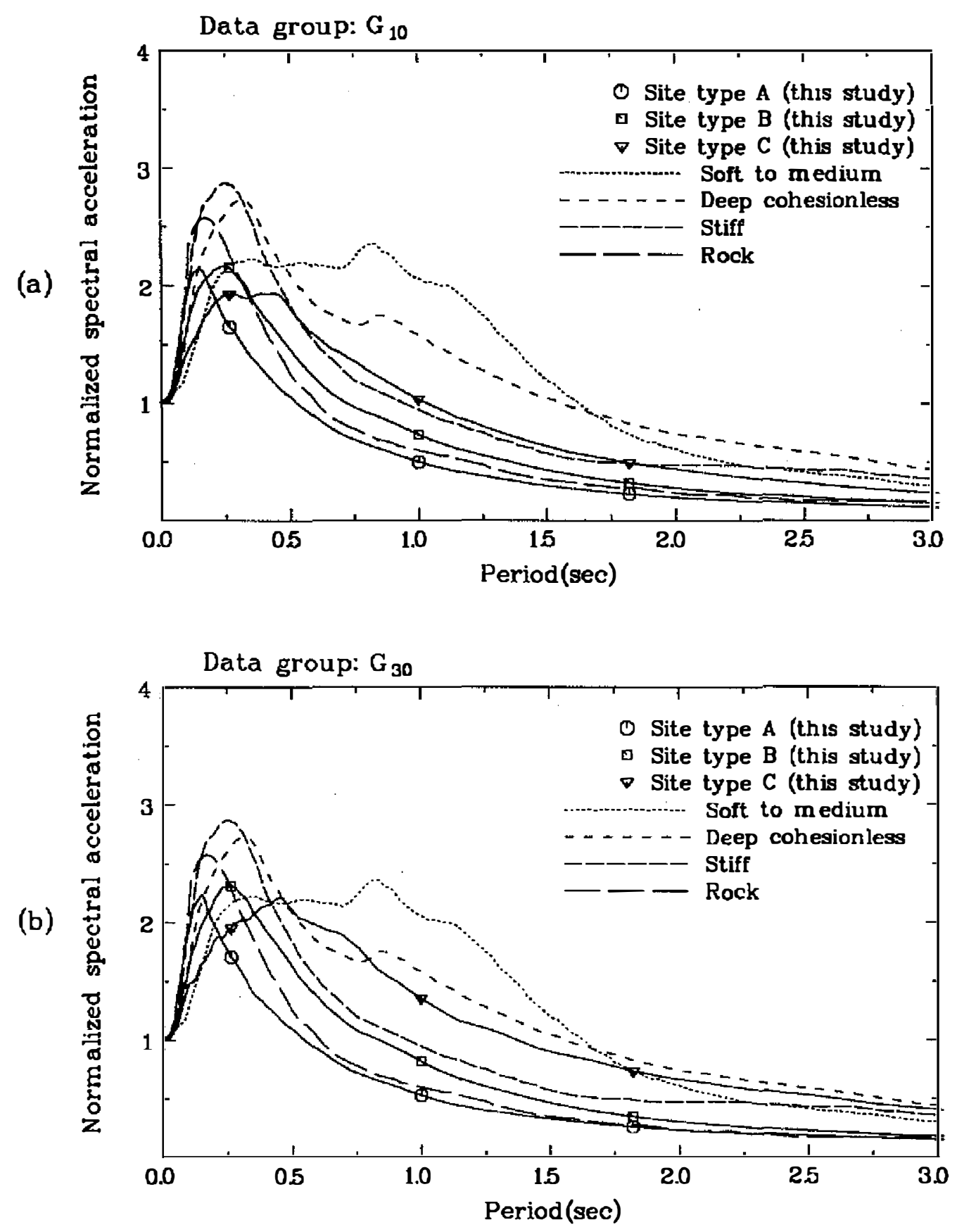

Fig. 2. Comparison of normalized 5\% damped response spectra of this study with the results of Seed et al.(1976). Plots a, b, c, and d are calculated from the data groups of $\mathrm{G}_{10}, \mathrm{G}_{30}, \mathrm{G}_{50}$ and $\mathrm{G}_{921}$ respectively. 

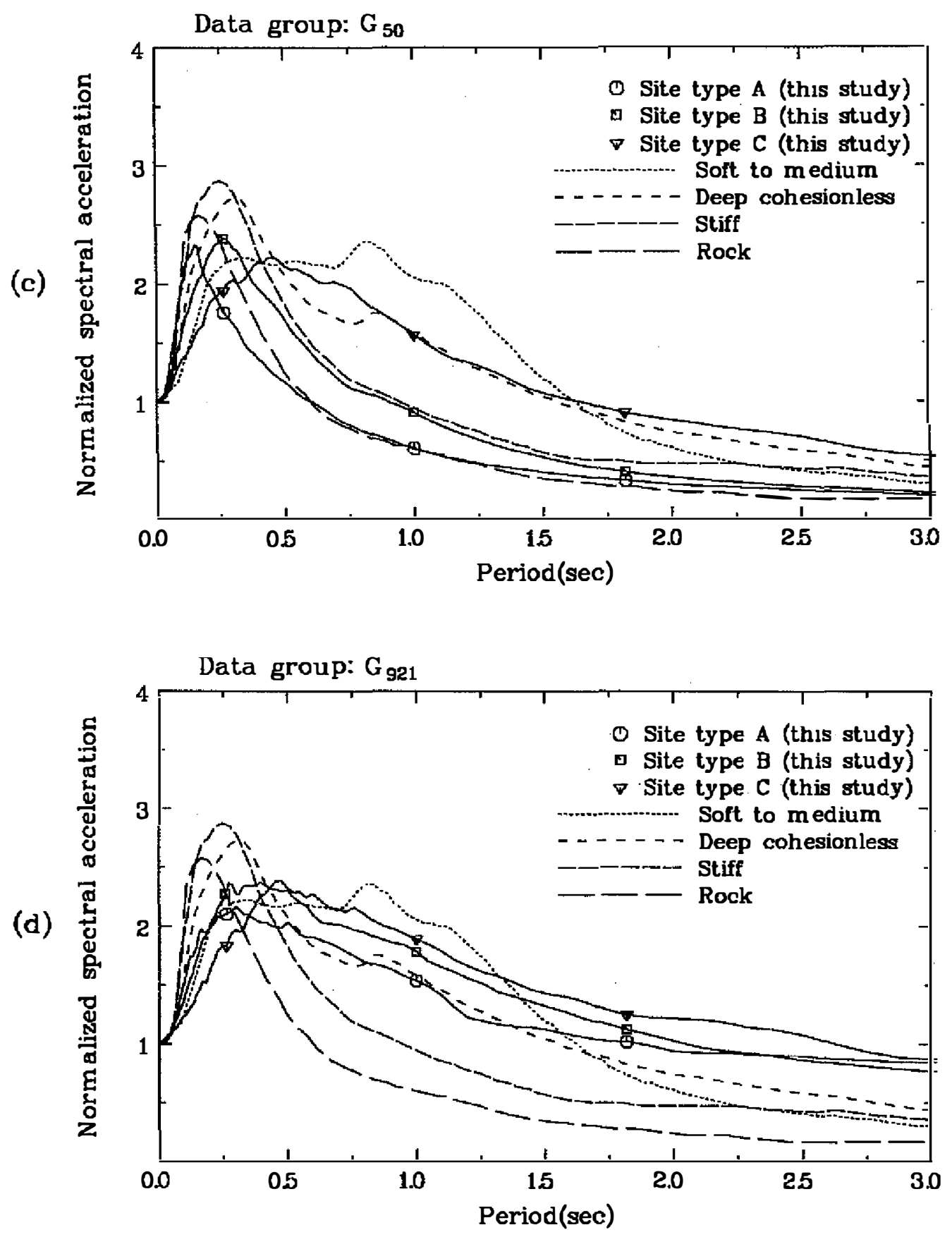

(Fig. 2. continued) 
$\mathrm{A} \rightarrow \mathrm{B} \rightarrow \mathrm{C}$. Thus, the amount of long-period energy depends not only on earthquake intensity but also on soil conditions of the site.

For the data group of $\mathrm{G}_{50}$ (Fig. 2c), the spectral shape of site type A, which is distributed widely over the whole study area, is similar to the "rock" site of Seed et al. (1976). Site type B, which is distributed widely, too, lies between the "stiff soil" and the "deep cohesionless soil". Site type C lies between the "deep cohesionless soil" and the "soft to medium clay and sand", the sites located along the Taan river, in Taichung county, almost all belong to this type. The peak spectral amplification factors are about 2.3 (at $0.18 \mathrm{~s}$ ) for type A, 2.4 (at $0.3 \mathrm{~s}$ ) for type B, and 2.2 (at $0.5 \mathrm{~s}$ ) for type $\mathrm{C}$.

For the data group of the Chi-Chi mainshock (Fig. 2d), the response spectra have greater long-period energy than those of the $\mathrm{G}_{50}$ data group, but the peak spectral amplification factors (about 2.2, 2.4, and 2.4 for type A, B, and C, respectively) are approximately equal to those of the $\mathrm{G}_{50}$ data group, only the dominant periods are slightly shifted to long period. In contrast, the accelerograms of the Chi-Chi mainshock in this study area can be considered the near-fault ground motions, so the spectral shape may represent the near-fault effect, which is significantly different from the shape of far field motions.

In general, the peak spectral amplification factors obtained in this study, 2.3, 2.4, and 2.2 (for $\mathrm{G}_{50}$ data group) for site types $\mathrm{A}, \mathrm{B}$, and $\mathrm{C}$, respectively, are smaller than those given by Seed et al. (1976), 2.6, 2.9, 2.8, and 2.4, suggesting that the site classification in this study is not appropriate, or the curves given by Seed et al.(1976) may not be useful for Taiwan areas.

\subsection{Comparison with the Current Design Code}

In order to understand the frequency contents of the response spectra, and to investigate the applicability of the current design code to the west-central Taiwan area, the comparisons of the mean plus one standard-deviation response spectra with the design code, normalized to $1 \mathrm{~g}$, are shown in Figs. 3 and 4. From these figures, it is clear that the mean plus one standarddeviation response spectra increase gradually from the data groups of $\mathrm{G}_{10} \rightarrow \mathrm{G}_{30} \rightarrow \mathrm{G}_{50} \rightarrow \mathrm{G}_{921}$, and the dominant periods of response spectra become larger and larger from the site types of $A \rightarrow B \rightarrow C$. This means that the softer the soil conditions are, the greater the long-period energy will be. The wider velocity-controlled platform for Chi-Chi mainshock is related to the high velocity ground pulse and the large PGD, which can raise the spectral shape to a very long period. This unusual spectral shape of near-field records is significantly different from that of far-field records (Huang and Chen 2000).

For the vertical component, the peak spectral acceleration of site type A (Fig. 3a) occurring at $0.07 \mathrm{~s}$, is about 3.0 , the peak spectral velocity and displacement occurring at $4 \mathrm{~s}$ and $6 \mathrm{~s}$, respectively. The peak spectral acceleration of site type B (Fig. $3 \mathrm{~b}$ ) occurring at $0.08 \mathrm{~s}$, is about 2.6 , the peak spectral velocity and displacement occurring at $5 \mathrm{~s}$ and $6 \mathrm{~s}$, respectively. The peak spectral acceleration of site type $C$ (Fig. 3c) occurring at $0.1 \mathrm{~s}$, is about 2.5 , the peak spectral velocity and displacement occurring at $5 \mathrm{~s}$ and $6 \mathrm{~s}$, respectively.

For the horizontal component, the peak spectral acceleration of site type A (Fig. 4a) occurring at $0.13 \mathrm{~s}$, is about 2.7 , the peak spectral velocity and displacement occurring at $6 \mathrm{~s}$ and $7 \mathrm{~s}$, respectively. The peak spectral acceleration of site type B (Fig. $4 \mathrm{~b}$ ) occurring at $0.25 \mathrm{~s}$, is 
RESPONSE SPECTRUM

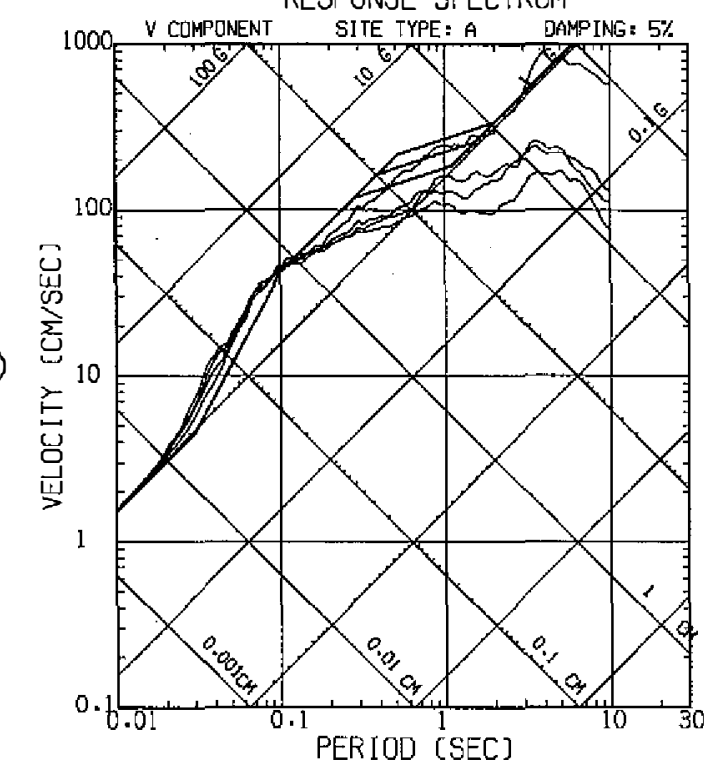

(b)
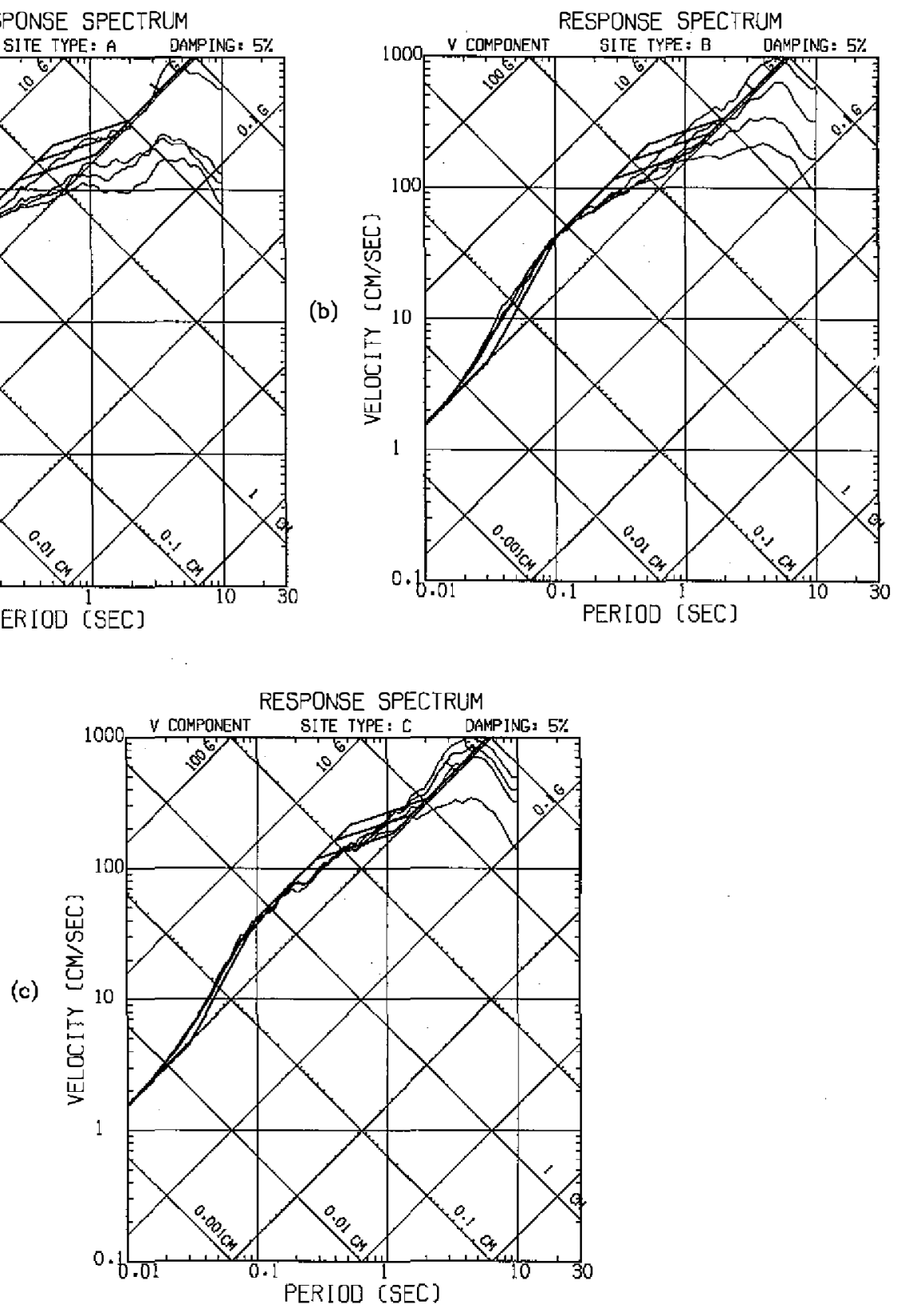

Fig. 3. Comparison of normalized 5\% damped mean plus one standard-deviation response spectra, the vertical component, with the current seismic design spectra. Four curves, from bottom to top, are calculated from the data groups of $\mathrm{G}_{10}, \mathrm{G}_{30}, \mathrm{G}_{50}$ and $\mathrm{G}_{921}$ respectively. Plots $\mathrm{a}, \mathrm{b}$, and $\mathrm{c}$ are site type $\mathrm{A}, \mathrm{B}$, and $\mathrm{C}$ respectively. 

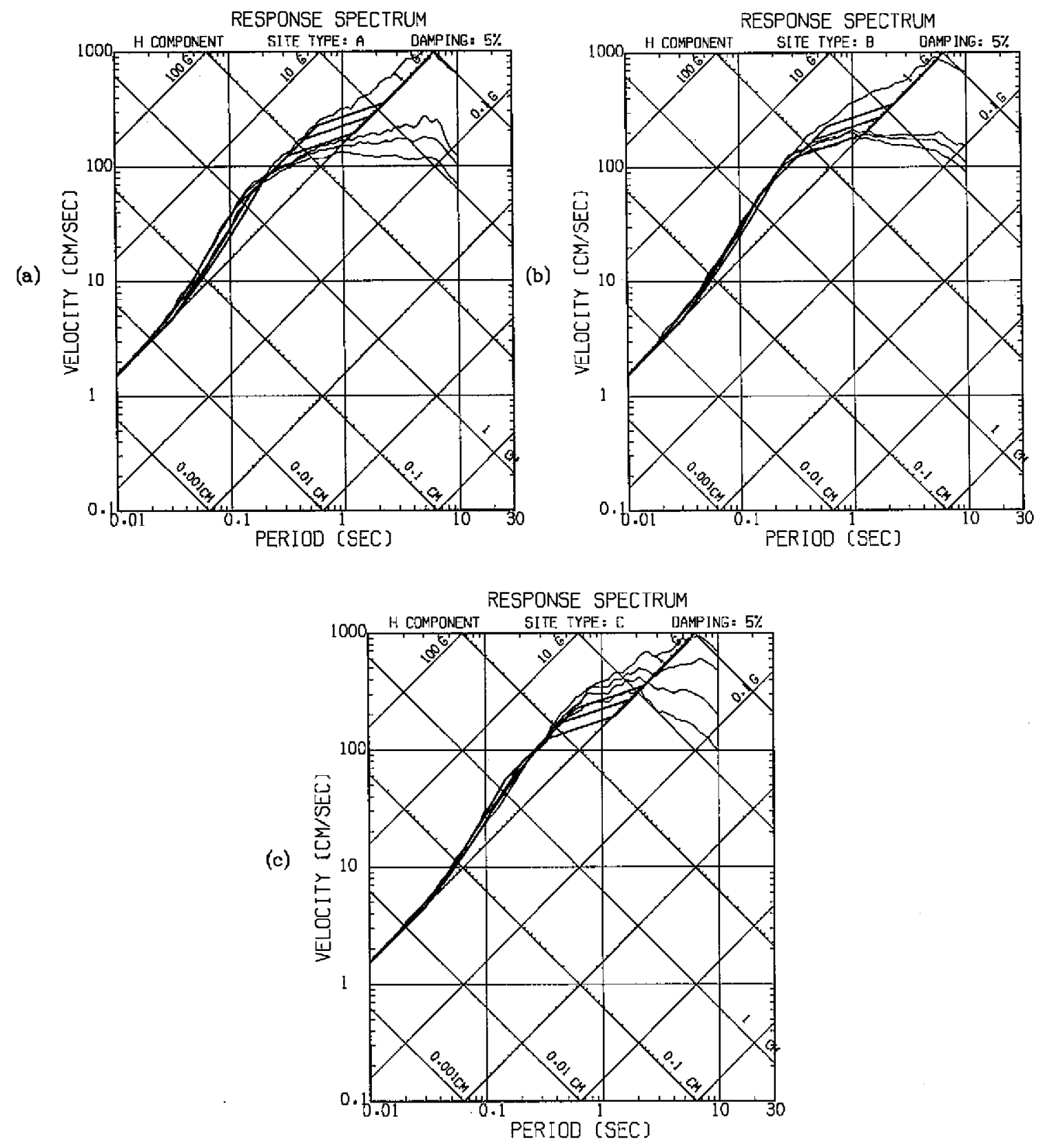

Fig. 4. Comparison of normalized 5\% damped mean plus one standard-deviation response spectra, the horizontal component, with the current seismic design spectra. Four curves, from bottom to top, are calculated from the data groups of $G_{10}, G_{30}, G_{50}$ and $G_{921}$ respectively. Plots $a, b$, and $c$ are site type $\mathrm{A}, \mathrm{B}$, and $\mathrm{C}$ respectively. 
about 2.8 , the peak spectral velocity and displacement for Chi-Chi mainshock occurring at $6 \mathrm{~s}$ and 10 s, respectively. The peak spectral acceleration of site type $C$ (Fig. $4 \mathrm{c}$ ) occurring at $0.6 \mathrm{~s}$, is about 3 , the peak spectral velocity and displacement for the Chi-Chi mainshock occurring at $7 \mathrm{~s}$ and 10 s, respectively.

Overall, the horizontal response spectra, only for site type A, are higher than the design code in periods less than $0.2 \mathrm{~s}$. However, the vertical components, for all site types, are significantly greater than the design code in periods less than $0.1 \mathrm{~s}$. This leads us to conclude that the vertical ground motion is usually associated with high-frequency energy. The response spectra of the Chi-Chi mainshock greater than the values of design code at the long-period ranges results from the extended rupture time of the Chelungpu fault. Therefore, a modified design code is necessary, especially in application to the near fault area.

\subsection{Comparisons between the Horizontal and Vertical Components}

Fig. 5 and Fig. 6 show the horizontal and vertical components of mean response spectra calculated for all stations, respectively. The total mean of 32 events are also shown in bold line. In horizontal or vertical components, the Chi-Chi earthquake series (No. 29 to 32), and the Ruey-Li earthquake (No. 25) have much greater response spectra than other events. For the sake of easy comparison, both components of these disastrous events are plotted together (Fig.

7). There are two important common features among these events:

(1) where the horizontal component of response spectrum is generally greater than the vertical component, it means that the shaking in the horizontal direction has larger destructive force than that in the vertical direction.

(2) where the dominant frequency in the horizontal component is lower than that in the vertical component: In horizontal component, the dominant frequencies are about $2.5 \mathrm{~Hz}$ for the Chi-Chi mainshock, $3.2 \mathrm{~Hz}$ for the Ruey-Li event, and $7 \mathrm{~Hz}$ for the total mean of 32 events. In vertical component, the dominant frequencies are about $8 \mathrm{~Hz}$ for the Chi-Chi mainshock, $3.6 \mathrm{~Hz}$ for the Ruey-Li event and $9 \mathrm{~Hz}$ for the total mean of 32 events, respectively. This result is consistent with the current design code in which the vertical component is greater than the horizontal component in the short-period range.

\subsection{Comparisons among the Different Frequency Bands}

Table 3 illustrates the geometric mean value of response spectra in different frequency bands of five disastrous earthquakes. In general, the low frequency band from 0.1 to $0.3 \mathrm{~Hz}$ can be considered an amplification region of displacement, which will produce maximum displacement response to structures. The intermediate frequency band from 0.3 to $3.3 \mathrm{~Hz}$ can be considered an amplification region of velocity, which will produce maximum velocity response to structures. Similarly, the high frequency band from 3.3 to $10 \mathrm{~Hz}$ for the horizontal component, and from 3.3 to $12 \mathrm{~Hz}$ for the vertical component, can be considered an amplification region of acceleration, which will produce maximum acceleration response to structures.

The response spectra of the Chi-Chi earthquake series are significantly larger than others. Of the mainshock, for instance, the vertical component of response spectra in full frequency 


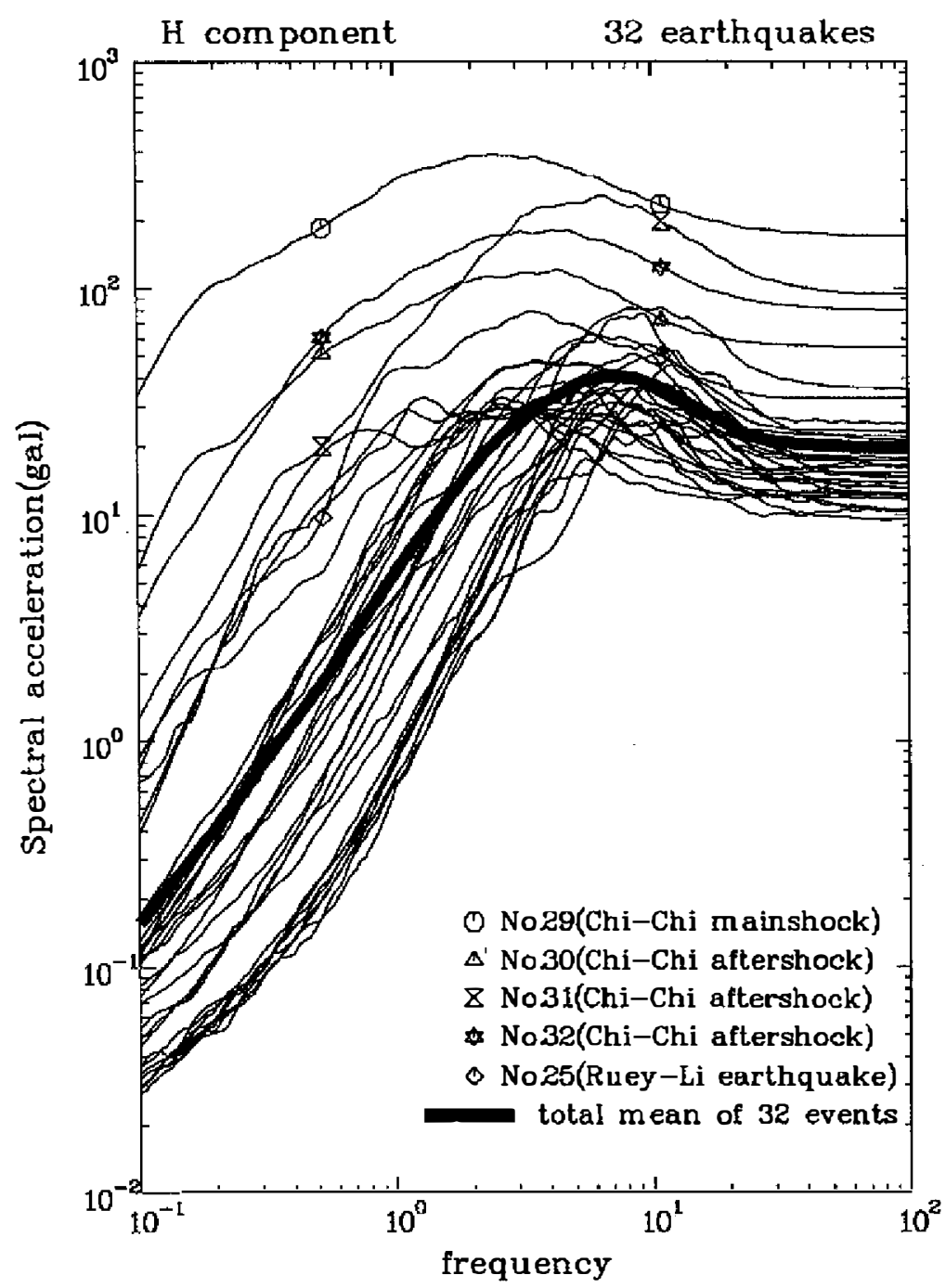

Fig. 5. Comparison among the 32 events. The mean of horizontal response spectra shown here is calculated from all the recording sites triggered by the same event. Five disastrous events are marked with the special symbols.

band from 0.1 to $100 \mathrm{~Hz}$, is only 37 times of total mean of 32 events, but the times to total mean in extremely high, high, intermediate, and low frequency bands are 12,14, 69, and 273, respectively. So, the times increase gradually when it approaches lower frequencies. The horizontal component in full frequency band is only 26 times of total mean, but the times to total mean in extreme high, high, intermediate, and low frequency bands are 8, 8, 51, and 228, respectively. These results are similar to the vertical component, only the times of vertical component are generally larger than those in horizontal component. This phenomenon is caused by the intensified vertical motion from the thrusting movement of the Chelungpu fault. 


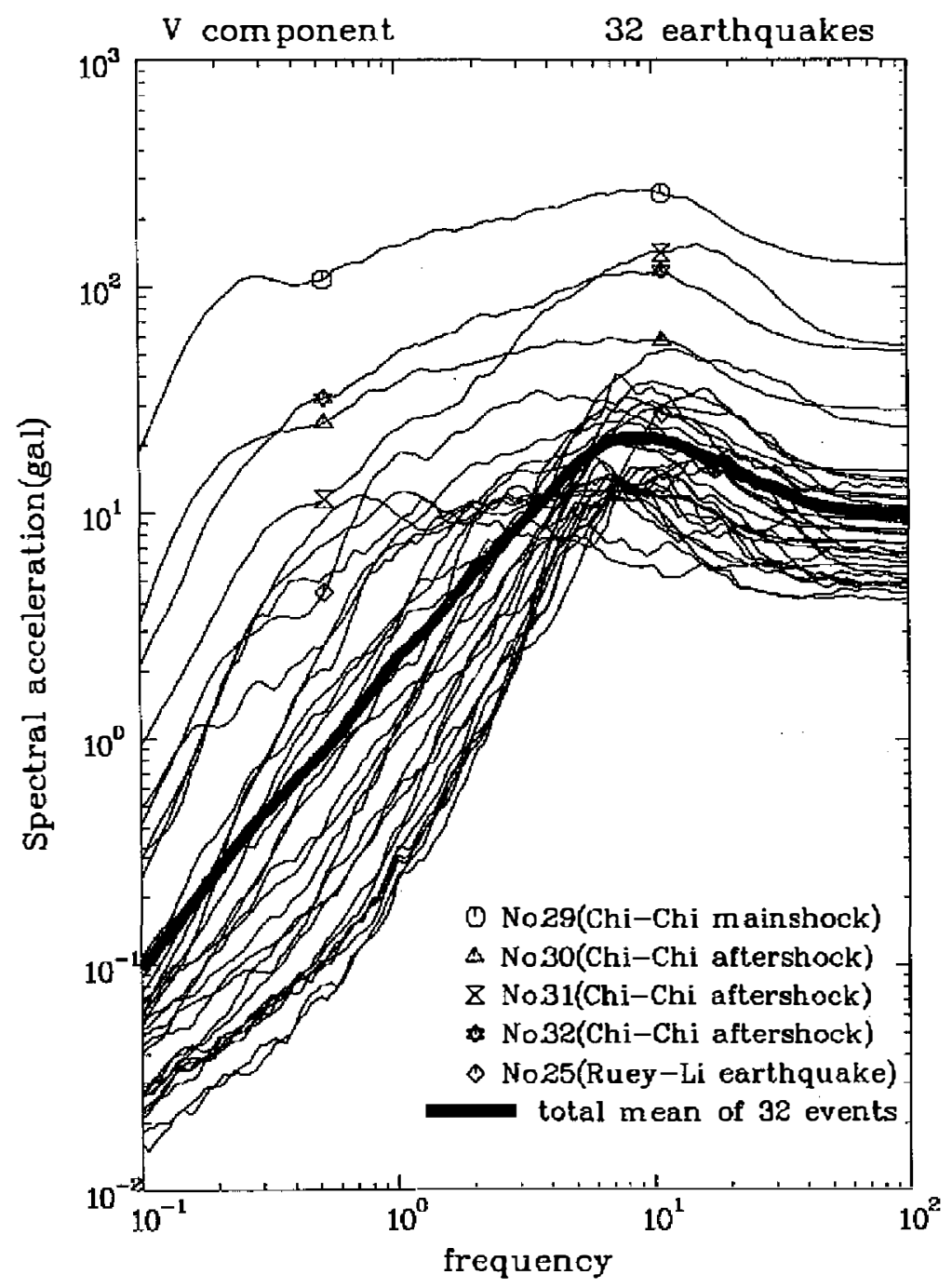

Fig. 6. Comparison among the 32 events. The mean of vertical response spectra shown here is calculated from all the recording sites triggered by the same event. Five disastrous events are marked with special symbols.

Of the Ruey-Li event, the vertical component of response spectra in full frequency band is only 3 times of the total mean of 32 events, but the times to total mean in extreme high, high, intermediate, and low frequency bands are 1.4, 1.8, 6, and 6, respectively. The horizontal component in full frequency band is also 3 times of total mean, and the times in extreme high, high, intermediate, and low frequency bands are $1.5,1.8,5$, and 7 , respectively. From these results, we found that the times of Ruey-Li event are almost equal in both directions, implying that the Ruey-Li earthquake has no strong thrusting movement of fault in the study area. On the other hand, although the times of the Ruey-Li event, like the Chi-Chi mainshock, increase 


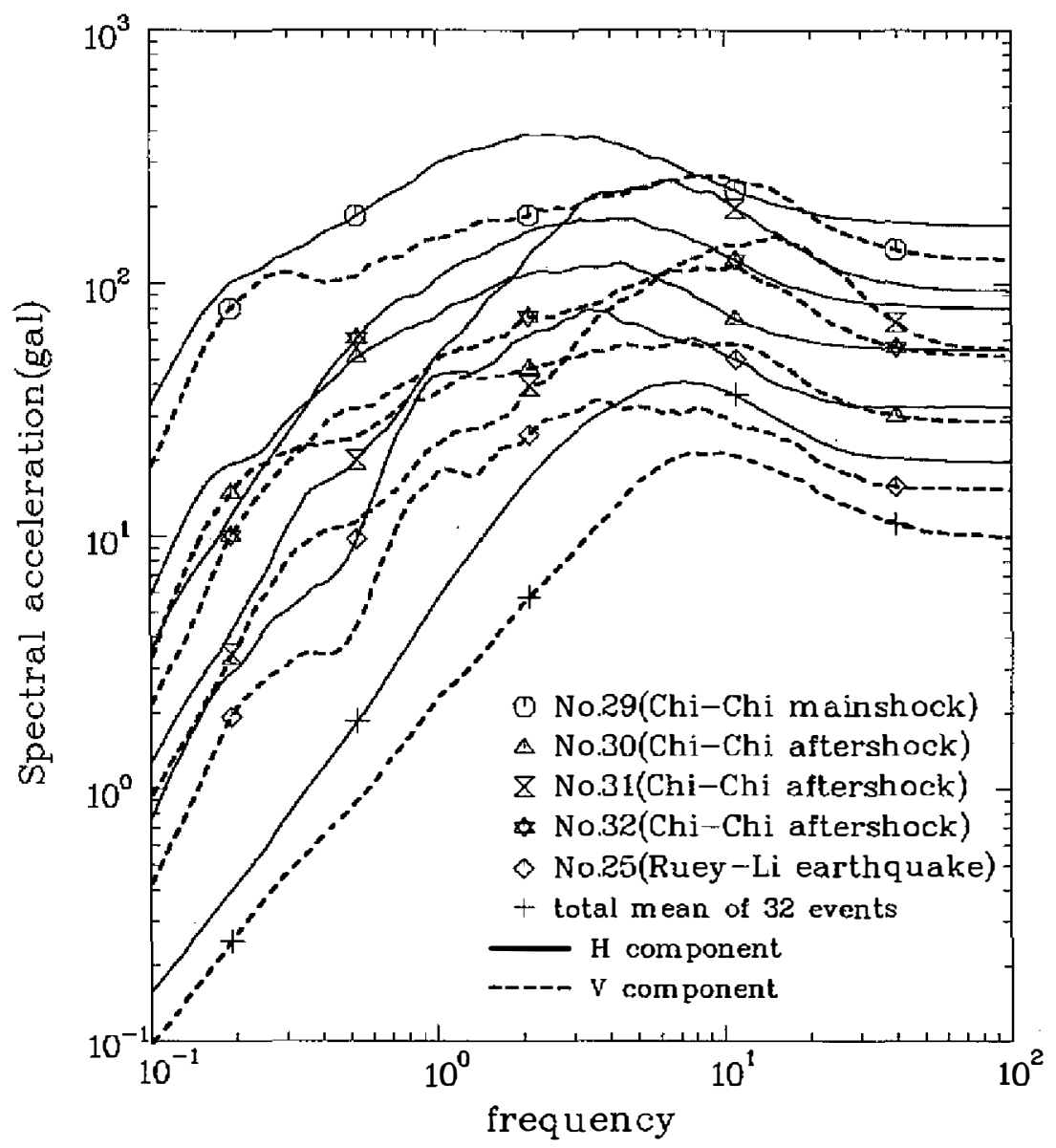

Fig. 7. Comparison among the five disastrous events. Broken line is the vertical component, the total mean of 32 events is also shown.

gradually when it approaches lower-frequencies, they are significantly less than those of the Chi-Chi mainshock. In the low-frequency band, particularly, the response spectra of the ChiChi mainshock are 273 and 228 times of the total mean of 32 event for the vertical and horizontal components, respectively. This surprisingly low-frequency energy will produce very huge displacement response to structures which have longer fundamental periods. It is evident that the longer the rupture time of the fault, the longer the period of energy release will be.

For the Chi-Chi mainshock, the response spectral ratios of vertical to horizontal component in low, intermediate, high, extreme high, and full frequency bands are $0.74,0.56,0.79$, 0.84 , and 0.71 , respectively. The same ratios for the Ruey-Li event are $0.59,0.44,0.48,0.51$, and 0.50 , respectively, and for the total mean of 32 events, the ratios are $0.62,0.41,0.47,0.55$, and 0.50 , respectively. Apparently, the ratios of the Chi-Chi mainshock are the largest among the 32 events. It is worth noting that the results of the Chi-Chi mainshock can be treated as the near-fault effects in west-central Taiwan. Thus, the characteristics of strong ground motions at 
Table 3. Geometric means of acceleration response spectra(in gal) of disastrous events in different frequency bands $($ in $\mathrm{Hz}$ ).

\begin{tabular}{|c|c|c|c|c|c|c|}
\hline Events & Comp. & $\begin{array}{l}\text { Low } \\
0.1 \sim 0.3\end{array}$ & $\begin{array}{c}\text { Intermediate } \\
0.3 \sim 3.3\end{array}$ & $\begin{array}{c}\text { High } \\
3.3 \sim 12(\mathrm{~V}) \\
3.3 \sim 10(\mathrm{H}) \\
\end{array}$ & $\begin{array}{l}\text { Extreme high } \\
>12(\mathrm{~V}) \\
>10(\mathrm{H})\end{array}$ & $\begin{array}{l}\text { Full } \\
0.1 \sim 100\end{array}$ \\
\hline MS & $\mathrm{V}$ & $57.32(273)$ & $145.12(69)$ & $245.28(14)$ & $156.81(12)$ & 141.19 (37) \\
\hline No. 29 & $\mathrm{H}$ & 77.55 (228) & $260.95(51)$ & 310.97 ( 8$)$ & $185.83(8)$ & $197.97(26)$ \\
\hline $\mathrm{M}_{\mathrm{L}}=7.3$ & $\mathrm{~V} / \mathrm{H}$ & 0.74 & 0.56 & 0.79 & 0.84 & 0.71 \\
\hline AS & $\mathrm{V}$ & 10.78 & 34.74 & 56.71 & 34.57 & 31.54 \\
\hline No. 30 & $\mathrm{H}$ & 15.09 & 69.69 & 102.42 & 58.55 & 54.98 \\
\hline$M_{L}=6.6$ & $\mathrm{~V} / \mathrm{H}$ & 0.71 & 0.50 & 0.55 & 0.59 & 0.57 \\
\hline $\mathrm{AS}$ & $\mathrm{V}$ & 2.67 & 20.79 & 104.97 & 86.54 & 31.57 \\
\hline No. 31 & $\mathrm{H}$ & 3.49 & 47.88 & 233.63 & 117.29 & 55.23 \\
\hline $\mathrm{M}_{\mathrm{L}}=6.8$ & VIH & 0.77 & 0.43 & 0.45 & 0.74 & 0.57 \\
\hline AS & $\mathrm{V}$ & 7.00 & 45.51 & 103.56 & 65.74 & 44.14 \\
\hline No. 32 & $\mathrm{H}$ & 9.70 & 90.99 & 162.22 & 89.65 & 69.81 \\
\hline $\mathrm{M}_{\mathrm{L}}=6.8$ & $\mathrm{~V} / \mathrm{H}$ & 0.72 & 0.50 & 0.64 & 0.73 & 0.63 \\
\hline Ruey-Lj & $\mathrm{V}$ & $1.33(6)$ & $11.74(6)$ & $31.54(1.8)$ & $18.13(1.4)$ & $11.42(3)$ \\
\hline No. 25 & $\mathrm{H}$ & $2.25(7)$ & $26.45(5)$ & $65.22(1.8)$ & $35.70(1.5)$ & $22.92(3)$ \\
\hline $\mathrm{M}_{\mathrm{L}}=6.2$ & $\mathrm{~V} / \mathrm{H}$ & 0.59 & 0.44 & 0.48 & $0.5 \mathrm{l}$ & 0.50 \\
\hline \multirow{3}{*}{$\begin{array}{l}\text { Total mean } \\
\text { of } 32 \text { vents }\end{array}$} & $\mathrm{V}$ & 0.21 & 2.10 & 17.21 & 12.82 & 3.78 \\
\hline & $\mathrm{H}$ & 0.34 & 5.12 & 36.80 & 23.31 & 7.60 \\
\hline & V/H & 0.62 & 0.41 & 0.47 & 0.55 & 0.50 \\
\hline
\end{tabular}

Note: (1) MS and AS represent the mainshock and aftershock, respectively, on the series of Chi-Chi earthquakes.

(2) The numbers in parenthesis are the spectral ratios of that event with the total mean.

near-fault areas are significantly different from those of far-field events. Furthermore, two foreign cases, Northridge earthquake, USA, 1994, and Kobe earthquake, Japan, 1995, also had similar features. Their PGA ratios of vertical to horizontal component become larger when it is near to the fault line (Bozorgnia et al. 1995). So, the criteria of the seismic resistant design for near fault areas should be upgraded, especially, in the vertical direction.

Interestingly, for all the disastrous earthquakes, and for the total mean of 32 events, too, the spectral ratios of vertical to horizontal component in the intermediate frequency band are the smallest among the five frequency bands, suggesting that the response (or velocity response) in the vertical direction, from 0.3 to $3.3 \mathrm{~Hz}$, is significantly smaller than that in the horizontal direction. This perhaps reflects the geological structures of the uppermost crust, but this will require further studies to be confirmed.

\section{CONCLUSIONS}

The characteristics of response spectra in west-central Taiwan are studied in regard to 
both of earthquake intensity and site type. In order to highlight the behavior of the Chi-Chi mainshock, the near-fault effects, several kinds of comparisons with other far-field events are made. The results are summarized below:

(1) For all kinds of site type, the response spectra increase with the earthquake intensity. The spectral shape in the long-period range becomes more predominant if the soil conditions become softer. The response spectra of the Chi-Chi mainshock are greater than the values given by Seed et al.(1976) at the periods from 1.5 to over 3 seconds.

(2) The spectral shape of site type A in this study is similar to "rock" of Seed et al. (1976), site type B lies between the "stiff soil" and the "deep cohesionless soil", and site type C lies between the "deep cohesionless soil" and the "soft to medium clay and sand". It is adequate to classify the sites as several types just by the dominant periods of the averaged response spectra, if the dominant ground periods are not available.

(3) Comparisons of the mean plus one standard-deviation response spectra with the current seismic design code: The horizontal component spectra, only for site type A, are greater than the design code at the periods below $0.2 \mathrm{~s}$. But, the vertical components for all site types are significantly higher than the design code at the periods below $0.1 \mathrm{~s}$. These facts imply that the vertical ground motions are usually associated with high-frequency energy. In the long-period range, the response spectra of the Chi-Chi mainshock are much higher than the design code; therefore, the current design code needs to be modified, especially for applications to the near-fault areas.

(4) The response spectra of five disastrous earthquakes are much greater than the total mean of 32 events, the times increase gradually as it approaches lower frequencies. In the full-frequency band, from 0.1 to $100 \mathrm{~Hz}$, the vertical response spectra of the Chi-Chi mainshock are only 37 times of the total mean of 32 event, but the times in the low-frequency band, from 0.1 to $0.3 \mathrm{~Hz}$, reach the value of 273 . The horizontal components in the full frequency band are only 26 times of the total mean of 32 events, but the times in the low-frequency band reach the value of 228 . This reveals that the longer the fault rupture time is, as the Chelungpu fault, the more the low-frequency energy is released. Of the Ruey-Li event, the vertical response spectra in extreme high, high, intermediate, and low-frequency bands are1. $4,1.8,6$, and 6 times of total mean of 32 events respectively, and those times in the horizontal component are $1.5,1.8,5$, and 7 , respectively. The times in both directions are almost equal, suggesting that the Ruey-Li earthquake has no thrusting movements in the study area.

(5) The response spectral ratios of vertical to horizontal components of the Chi-Chi mainshock almost exceed $2 / 3$ in each frequency band, and these ratios are the largest among the 32 events. This result is caused by the intensified vertical motions from the thrusting movement of the Chelungpu fault. From cases of domestic and foreign events, the criteria of seismic design code for near-fault areas should be upgraded, especially, for the vertical component.

Acknowledgments The authors would like to thank the Seismological Observation Center of CWB for providing the strong motion data. We sincerely thank Mr. M. W. Huang, Institute of Earth Sciences, Academia Sinica, for his useful suggestions to improve this work. We also 
would like to express appreciation to Miss Y. C. Lai, the librarian of Nankai College, for her helping to collect the papers. This research was partially supported by the National Science Council under grant NSC90-2116-M-252-001.

\section{REFERENCES}

Bozorgnia, Y., M. Niazi, and K. W. Campbell, 1995: Characteristics of free-field vertical ground motion during the Northridge earthquake. Earthquake spectra, 11, 515-525.

Chai, J. F., C. H. Loh, and C. Y. Chen, 2000: Consideration of the near-fault effect on seismic design code for sites near the Chelungpu fault. J. Chinese Inst. Eng., 23, 447-454.

Chen, L. Y., 1994: Seismic amplification of soil layers in Taipei basin. Ph.D. thesis (in Chinese), National Taiwan University, Taipei, Taiwan, ROC.

Chen, S. S., and D. S. Cheng, 2000: Site-dependent characteristics for earthquakes in Taiwan region. J. Chinese Ins. of Civil and Hydraulic Eng., 12, 445-453.

Chen, S. S., F. J. Wang, and W. C. Hsu, 2000: The vibration periods and design spectra of Taipei basin. J. Architecture, 33, 103-118.

Hong, L. L., and C. H. Chang, 1993: Uniform hazard response spectra in Kaohsiung. J. Chinese Ins. of Civil and Hydraulic Eng., 5, 133-142.

Huang, C. T., and S. S. Chen, 2000: Near-field characteristics and engineering implications of the 1999 Chi-Chi earthquake. Earthq. Eng. Eng. Seis., 2, 23-41.

Loh, C. H., Y. T. Yeh, and W. Y. Jean, 1991: Development of site-dependent design spectra and a seismic risk map for the Taiwan area. J. Chinese Inst. Eng.,14, 437-446.

Mohraz, B., 1976: A study of earthquake response spectra for different geological conditions. Bull. Seis. Soc. Am., 66, 915-935.

Newmark, N. M., J. A. Blume, and K. K. Kapur, 1973: Seismic design spectra for nuclear power plants. J. Power Div. ASCE, 99, PO2, 287-303.

Saffarini, H. S., and H. Kabalawi, 1999: Design response spectra for Aqaba city-Jordan. Earthquake Eng. Struct. Dyn., 28, 725-739.

Seed, H. B., and I. M. Idriss, 1969: Influence of soil conditions on ground motions during earthquakes. J. Soil Mech. Found. Div. ASCE, 95, SM1, proc. 6347.

Seed, H. B., C. Ugas, and J. Lysmer, 1976: Site-dependent spectra for earthquake-resistant design. Bull. Seis. Soc. Am., 59, 221-243.

Tsai, C. C., Y. T. Yeh, K. L. Wen, S. N. Cheng, and M. H. Kao, 1986: The Hualien earthquake of May 20, 1986:strong ground motion data and response spectra. Bull. Inst. Earth Sciences, Academia Sinica, 6, 29-64, December.

Tsai, C. C., and I. C. Tsai, 1987: Proposed design response spectra for Taipei metro-politan area rapid transit system. CEER, R76-22, National Taiwan University.

Tsai, Y. B., and M. W. Huang, 2000: Strong ground motion characteristics of the Chi-Chi, Taiwan earthquake of September 21, 1999. Earthquake Eng. Eng. Seism., 2, 1-21.

Wang, J. H., C. Y. Wang, C. Y. Huang, T. C. Shin, S. B. Yu, S. F. Hsieh, and K. L. Wen, 2000: Program for earthquake and active-fault researches, Proceedings, International 
workshop on the September 21, 1999 Chi-Chi earthquake. 185-192.

Wen, K. L., 1988: Characteristics of the strong ground motions in Lotung. Ph.D. thesis(in Chinese), National Central University, Chungli, Taiwan, ROC. 